\title{
The dominance of a multiresistant strain of Neisseria gonorrhoeae among prostitutes and STD patients in The Gambia
}

\author{
C A Ison, J Pepin, N S Roope, E Demba, O Secka, C S F Easmon
}

\begin{abstract}
Objective-To study the epidemiology of antibiotic resistant strains of Neisseria gonorrhoeae from sexually transmitted disease clinics in The Gambia.

Materials and methods-One hundred and sixty five strains of $\boldsymbol{N}$ gonorrhoeae were tested for their antibiotic susceptibility, auxotype, serotype, and plasmid content.

Results-Of the total population 84 (51\%) were non-penicillinase producing (nonPPNG) and 81 (49\%) penicillinaseproducing $\boldsymbol{N}$ gonorrhoeae (PPNG). There were 16 serovars, five auxotypes and 33 auxotype/serovar (A/S) classes in the total population and the nonPPNG. Among PPNG only five serovars, two auxotypes and nine A/S classes were found. One A/S class predominated, NR/B-7 (86 isolates), of which $66(77 \%)$ were PPNG and the remainder were chromosomally-mediated resistant $\boldsymbol{N}$ gonorrhoeae (CMRNG). These strains also showed reduced susceptibility to ciprofloxacin, ceftriaxone and tetracycline and were evenly distributed among patient groups.

Conclusion-We have identified a relatively homogeneous gonococcal population with a core group of isolates exhibiting high levels of antibiotic resistance.
\end{abstract}

(Genitourin Med 1992;68:356-360)

\section{Introduction}

In many African countries the incidence of gonorrhoea is high ${ }^{1}$ and effective therapy is hampered by resistance to low cost antibiotics. Since plasmid-mediated resistance was first described in 1976, infections caused by penicillinase-producing $N$ gonorrhoeae (PPNG) have been reported from many African countries $^{2-11}$ including the West African countries of The Gambia ${ }^{25}$ and Senegal. ${ }^{89}$ Their prevalence has continued to rise because more effective antibiotics such as spectinomycin, ceftriaxone and ciprofloxacin have been either unavailable or too expensive. Chromosomal resistance to penicillin has also been described ${ }^{9}$ but less extensively.

The epidemiology of antibiotic resistance in $N$ gonorrhoeae has been poorly studied until recent years because of the lack of suitable tools. The use of auxotyping ${ }^{12}$ and serotyping ${ }^{13}$ has allowed such studies in the developed world but as yet there is only limited information regarding $N$ gonorrhoeae auxotypes and serotypes in African countries apart from a previous study from The Gambia ${ }^{5}$ and from Kenya. ${ }^{114}$

We have studied strains of $N$ gonorrhoeae from patients in The Gambia and have used these techniques to examine the distribution of antibiotic resistance in this population.

\section{Materials and methods}

Bacterial isolates

Two hundred and forty nine isolates of $N$ gonorrhoeae were collected between January 1989 and July 1990 from all patients with gonorrhoea attending the Medical Research Council outpatient clinics in Fajara and Farafenni, The Gambia, West Africa which are 180 kilometers apart on the main route between Dakar and the southern part of Senegal. These two clinics provide general outpatient services and approximately 5-10 patients per week are seen with sexually transmitted diseases. The patients included: men presenting with a urethral discharge, women (most of them prostitutes) presenting with abnormal pain or vaginal discharge and female prostitutes examined during a cross-sectional survey of all prostitutes working in The Gambia. ${ }^{15}$ Specimens from each patient were inoculated onto Thayer Martin medium directly, transported to the laboratory and incubated for 24-48 hours in carbon dioxide enriched environment using candle extinction jars. Colonies were confirmed by Gram stain, oxidase reaction, and utilisation of glucose but not maltose or sucrose using Minitek kits (Becton Dickinson UK Ltd), and stored frozen and transported to St Mary's Hospital Medical School for further characterisation. Upon receipt, strains were recovered on GC agar base $(36 \mathrm{~g} / \mathrm{l}$, Difco Laboratories) supplemented with $1 \%$ IsoVitaleX. One hundred and seventy isolates (68\%) were recovered and used in this study.

\section{Antibiotic susceptibility}

Penicillinase-producing isolates were detected using the chromogenic cephalosporin, Nitrocefin (Unipath Ltd). The minimum inhibitory concentration (MIC) of all isolates was determined using an agar dilution technique. The medium was Diagnostic Sensitivity Test (DST) agar (Unipath Ltd) supplemented with 5\% lysed horse blood (Tissue Culture Services) and $1 \%$ IsoVitaleX and the inoculum was $10^{4}$ colony forming units (cfu). The inoculated media were incubated at $36^{\circ} \mathrm{C}$ in $6 \%$ carbon dioxide for 48 hours and the endpoint read as the lowest concentration giving complete inhibition. The antibiotics tested were peni- 
Table 1 Distribution of serovars and auxotypes among 165 isolates of Neisseria gonorrhoeae

\begin{tabular}{|c|c|c|c|c|c|c|}
\hline \multirow[b]{2}{*}{ Serovar } & \multirow[b]{2}{*}{ Total no (\%) } & \multicolumn{5}{|l|}{ Auxotype } \\
\hline & & $\begin{array}{l}\text { Total no I } \\
{ }^{*} N R\end{array}$ & $\begin{array}{c}\text { of } P P N G] \\
\star P R O\end{array}$ & ${ }^{\star} A R G$ & ${ }^{*} P R O / A R G$ & ${ }^{\star} H Y X$ \\
\hline $\begin{array}{l}\text { 1B-7 } \\
1 \mathrm{~A}-2 \\
1 \mathrm{~A}-6 \\
1 \mathrm{~B}-2 \\
1 \mathrm{~B}-3 \\
1 \mathrm{~B}-8 \\
1 \mathrm{~B}-1 \\
1 \mathrm{~B}-5 \\
1 \mathrm{~B}-19 \\
1 \mathrm{~A}-4 \\
\text { Others } \\
\text { Non-typable }\end{array}$ & $\begin{array}{l}93(56) \\
13(7) \\
9(5) \\
6(4) \\
6(4) \\
5(3) \\
5(3) \\
6(4) \\
6(4) \\
3(2) \\
8(5) \\
5(3)\end{array}$ & $\begin{array}{l}86[66] \\
5[1] \\
3 \\
1 \\
2 \\
3 \\
4 \\
3[2] \\
6[3] \\
3 \\
5[1] \\
5[3]\end{array}$ & $\begin{array}{l}7[2] \\
6[2] \\
4 \\
4 \\
1 \\
1[1] \\
\\
3\end{array}$ & $\begin{array}{l}2 \\
1 \\
1 \\
2\end{array}$ & $\begin{array}{l}2 \\
1 \\
2\end{array}$ & 2 \\
\hline
\end{tabular}

$\star$ NR-Non-requiring.

*PRO-Proline-requiring.

*ARG-Arginine-requiring.

${ }^{\star}$ PRO/ARG-Proline/Arginine-requiring.

${ }^{\star} \mathrm{HYX}$-Hypoxanthine-requiring.

Others = 1A-1 (1 isolate), 1A-12 (3), 1A-18 (1), 1B-4 (1), IB-6 (1), IB-26 (1)

cillin (0.008-4 mg/1, Mast Laboratories); ceftriaxone $(0.001-1 \mathrm{mg} / \mathrm{l}$, Roche Products Ltd); ciprofloxacin $(0.001-1 \mathrm{mg} / \mathrm{l}$, Bayer UK); spectinomycin (2-64 $\mathrm{mg} / \mathrm{l}$, Mast Laboratories); tetracycline $(0.008-8 \mathrm{mg} / \mathrm{l})$, Sigma Chemicals Ltd) and thiamphenicol $(0 \cdot 12-8 \mathrm{mg} / \mathrm{l}$, Sigma). All isolates were screened for high-level tetracycline resistance on a medium containing GC agar base (Difco Laboratories) supplemented with $1 \%$ IsoVitaleX and $10 \mathrm{mg} / 1$ tetracycline, incubated for 24 hours at $36^{\circ} \mathrm{C}$ in $6 \%$ carbon dioxide and scored for the presence and absence of growth.

\section{Auxotyping}

A modification of the method of Copley and Egglestone $^{16}$ was used to determine the requirement for proline, arginine, hypoxanthine, uracil, histidine and methionine. Arginine requiring isolates were also cultured on media to determine their ability to utilise ornithine as an alternative substrate. Inocula of $10^{4} \mathrm{cfu}$ were incubated at $36^{\circ} \mathrm{C}$ in $6 \%$ carbon dioxide and examined for the presence of macrocolonies at 24 hours.

\section{Serotyping}

The GS panel of twelve monoclonal antibodies linked to staphylococcal Protein A was used in a coagglutination system. ${ }^{13} \mathrm{~A}$ cloudy suspension of each strain was prepared in phosphate buffered saline (PBS) and boiled for $10 \mathrm{~min}$ utes. One drop of the suspension was mixed with an equal volume of each monoclonal reagent and allowed to rotate on a glass slide for exactly two minutes. The pattern of agglutination designated the serovar using the nomenclature of Knapp et al. ${ }^{13}$ Isolates that did not react with the GS panel were serotyped using the $\mathrm{Ph}$ panel and the nomenclature of Bygdeman et al. ${ }^{17}$ These assays were kindly performed by Dr Hugh Young, Edinburgh, Scotland.

\section{Plasmid analysis}

PPNG were grown overnight on GC Agar Base (Difco) supplemented with $1 \%$ IsoVitaleX and penicillin $(1 \mathrm{mg} / \mathrm{l})$ to enhance plasmid production. The growth was harvested in saline and plasmids extracted according to the rapid method of Birnboim and Doly. ${ }^{18}$ Plasmid extractions were electrophoresed in $1.0 \%$ agarose gels in $20 \mathrm{mM}$ sodium acetate buffer $\mathrm{pH} 7.8$ and stained with ethidium bromide $(1 \mathrm{mg} / \mathrm{l})$ for $1 / 2$ hour and visualised on the transilluminator.

\section{Statistical analysis}

Proportions were compared using the chi square test.

\section{Results}

One hundred and seventy isolates of $N$ gonorrhoeae cultured from 165 patients were studied. The extra five isolates were from patients in whom initial treatment was unsuccessful These pairs of isolates were found to be identical and therefore only one isolate of each pair was considered in the overall analysis. Of the 165 patients, 91 were women and 74 men.

Table 2 Distribution of antimicrobial susceptibility among PPNG and non-PPNG

\begin{tabular}{|c|c|c|c|c|c|c|}
\hline \multirow[b]{2}{*}{$M I C(m g / l)$} & \multicolumn{3}{|c|}{$\begin{array}{l}\text { PPNG } \\
\text { (Number of isolates, \%) }\end{array}$} & \multicolumn{3}{|c|}{$N O N-P P N G$} \\
\hline & $\begin{array}{l}\text { Total } \\
(n=81)\end{array}$ & $\begin{array}{l}\text { NR/IB-7 } \\
(n=66)\end{array}$ & $\begin{array}{l}\text { Others } \\
(n=15)\end{array}$ & $\begin{array}{l}\text { Total } \\
(n=84)\end{array}$ & $\begin{array}{l}\text { NR/IB-7 } \\
(n=20)\end{array}$ & $\begin{array}{l}\text { Others } \\
(n=64)\end{array}$ \\
\hline $\begin{array}{l}\text { Penicillin } \\
\geqslant 4.0 \\
2.0 \\
1.0 \\
0.5-0.12 \\
\leqslant 0.06\end{array}$ & $\begin{array}{l}79(97) \\
2(3) \\
0 \\
0 \\
0\end{array}$ & $\begin{array}{l}66(100) \\
0 \\
0 \\
0 \\
0\end{array}$ & $\begin{array}{l}13(87) \\
2(13) \\
0 \\
0 \\
0\end{array}$ & $\begin{array}{c}2(2) \\
34(41) \\
8(10) \\
23(27) \\
17(20)\end{array}$ & $\begin{array}{l}2(10) \\
16(80) \\
2(10) \\
0 \\
0\end{array}$ & $\begin{array}{c}0 \\
18(28) \\
6(9) \\
23(36) \\
17(27)\end{array}$ \\
\hline $\begin{array}{c}\text { Ciprofloxacin } \\
0.06 \\
0.03 \\
0.015 \\
\leqslant 0.008\end{array}$ & $\begin{array}{l}0 \\
8(10) \\
57(70) \\
16(20)\end{array}$ & $\begin{array}{l}0 \\
8(12) \\
50(76) \\
8(12)\end{array}$ & $\begin{array}{l}0 \\
0 \\
7(47) \\
8(53)\end{array}$ & $\begin{array}{c}1(1) \\
3(4) \\
32(38) \\
48(57)\end{array}$ & $\begin{array}{c}0 \\
0 \\
16(80) \\
4(20)\end{array}$ & $\begin{array}{c}1(1) \\
3(5) \\
16(25) \\
44(69)\end{array}$ \\
\hline $\begin{array}{c}\text { Ceftriaxone } \\
0.06 \\
0.03 \\
0.015 \\
\leqslant 0.008\end{array}$ & $\begin{array}{c}0 \\
1(1) \\
36(44) \\
44(55)\end{array}$ & $\begin{array}{l}0 \\
0 \\
34(52) \\
32(48)\end{array}$ & $\begin{array}{l}0 \\
1(7) \\
2(13) \\
12(80)\end{array}$ & $\begin{array}{c}1(1) \\
0 \\
24(29) \\
59(70)\end{array}$ & $\begin{array}{l}0 \\
0 \\
16(80) \\
4(20)\end{array}$ & $\begin{array}{c}1(1) \\
0 \\
8(13) \\
55(86)\end{array}$ \\
\hline $\begin{array}{c}\text { Tetracycline } \\
8 \cdot 0 \\
4 \cdot 0 \\
2.0 \\
1.0 \\
0.5 \\
\text { NT }^{\star}\end{array}$ & $\begin{array}{c}13(16) \\
57(71) \\
9(11) \\
1(1) \\
0 \\
1(1)\end{array}$ & $\begin{array}{l}10(15) \\
54(83) \\
1(1) \\
0 \\
0 \\
1(1)\end{array}$ & $\begin{array}{l}3(20) \\
3(20) \\
8(53) \\
1(7) \\
0 \\
0\end{array}$ & $\begin{array}{c}5(6) \\
38(45) \\
30(36) \\
6(7) \\
4(5) \\
1(1)\end{array}$ & $\begin{array}{c}1(5) \\
19(95) \\
0 \\
0 \\
0 \\
0\end{array}$ & $\begin{array}{c}4(6) \\
19(31) \\
30(47) \\
6(9) \\
4(6) \\
1(1)\end{array}$ \\
\hline
\end{tabular}

*Not available for testing. 
Seventy-three of the 91 women were known prostitutes who were either screened as part of a survey ${ }^{15}$ or attended because of symptoms. A further 18 were not known prostitutes and were classed as STD Clinic attenders.

Eighty four $(51 \%)$ of the 165 gonococcal isolates were nonPPNG, 81 (49\%) being PPNG. In the total gonococcal population and among the nonPPNG there were 16 serovars, five auxotypes and 33 auxotype/serovar (A/S) classes. The distribution of these characteristics among the PPNG was more restricted: five serovars (plus one non-typable isolate), two auxotypes and nine A/S classes. This is all shown in table 1 .

One A/S class, NR/IB-7 represented 86 $(52 \%)$ of all the gonococcal isolates, the majority, 66 (77\%), being PPNG. Thus 66 ( $81 \%$ ) of the 81 PPNG isolated were NR/IB-7, a striking homogeneity contrasted with the heterogeneity of the nonPPNG isolates where A/S class NR/IB-7 only accounted for $24 \%$ of the isolates. Five isolates were not typable by the standard GS panel of antibodies. All five, however, did type as serovar AvBx using the $\mathrm{Ph}$ panel.

The susceptibility of the 165 isolates to penicillin, ciprofloxacin, ceftriaxone and tetracycline is shown in table 2 . Given the prominence of NR/IB-7 isolates in this population we have shown their susceptibility separately in the table. All isolates were sensitive to spectinomycin (MIC $\leqslant 32 \mathrm{mg} / \mathrm{l}$ ). Of the 84 nonPPNG isolates $44(52 \%)$ had a penicillin MIC of $\geqslant 1.0 \mathrm{mg} / \mathrm{l}$ and would therefore be considered CMRNG. All the 20 nonPPNG NR/IB-7 isolates were CMRNG.

In contrast to penicillin, the relationship of both ciprofloxacin and ceftriaxone MICs to clinical failure is not well established. With both agents we therefore took a concentration of $\geqslant 0.015 \mathrm{mg} / \mathrm{l}$ as an arbitrary cut off between full sensitivity and reduced susceptibility. This concentration was chosen because we have shown it to be useful in monitoring drifts of reduced susceptibility in a previous study. ${ }^{19} \mathrm{At}$ this level rather more PPNG than nonPPNG $(80 \%$ vs $32 \%, p=<0.001)$ showed reduced susceptibility to ciprofloxacin in the total population. The majority ( $89 \%$ ) of the PPNG with reduced ciprofloxacin susceptibility were NR/IB-7, compared with a figure of only $44 \%$ for nonPPNG. A similar trend was seen with ceftriaxone, more PPNG than nonPPNG having a MIC of $\geqslant 0.015 \mathrm{mg} / 1(45 \%$ vs $30 \%$, $p=0.5)$ and the contribution of the NR/IB-7 isolates to this being greater among PPNG than nonPPNG. While this may indicate a trend towards reduction in susceptibility to

Table 3 Distribution of isolates of $A / S$ class NR/1B-7 among different patient groups

\begin{tabular}{lllll}
\hline & \multicolumn{5}{c}{$\begin{array}{l}\text { Patient group } \\
\text { (Number of isolates, \%) }\end{array}$} \\
\cline { 3 - 5 } Isolates of NR/IB-7 & $\begin{array}{l}\text { Total population } \\
(n=165)\end{array}$ & $\begin{array}{l}\text { Prostitutes } \\
(n=73)\end{array}$ & $\begin{array}{l}\text { Women }(S T D) \\
(n=18)\end{array}$ & $\begin{array}{l}\text { Men } \\
(n=74)\end{array}$ \\
\hline Total & $86(52)$ & $36(49)$ & $6(33)$ & $44(60)$ \\
PPNG & $66(40)$ & $28(38)$ & $5(28)$ & $33(45)$ \\
nonPPNG & $20(12)$ & $8(11)$ & $1(5)$ & $11(15)$ \\
\hline
\end{tabular}

these agents in the NR/IB-7 isolates we did not see any that showed a high-level of resistance to either compound (MIC, $\geqslant 0.12 \mathrm{mg} / \mathrm{l}$ ).

Tetracycline was the standard treatment for gonorrhoea in these clinics. We found no isolates with a tetracycline MIC of more than $10 \mathrm{mg} / \mathrm{l}$ that would indicate the presence of high-level plasmid-mediated tetracycline resistant strains. However, chromosomal resistance to tetracycline was high with 70 of $81(86 \%)$ PPNG and 43 of $84(51 \%)$ nonPPNG isolates having MICs of $\geqslant 4 \mathrm{mg} / \mathrm{l}$. All the five tetracycline treatment failures encountered had gonococcal isolates with tetracycline MICs of $4 \mathrm{mg} / \mathrm{l}$ (one patient) or $8 \mathrm{mg} / 1$ (four patients). The NR/IB-7 isolates in this study were again more resistant to tetracycline than the whole gonococcal population. We also tested the susceptibility of 154 of 165 strains (72 PPNG and 82 nonPPNG) to thiamphenicol and found $44(61 \%)$ of the PPNG and $34(42 \%)$ of the nonPPNG to have a $\mathrm{MIC}>1 \mathrm{mg} / \mathrm{l}$.

All the NR/IB-7 isolates carried the 2.6 and 24.5 MDa plasmids. In addition the $66 \mathrm{NR}$ IB-7 PPNG had the $3.2 \mathrm{MDa}$ penicillinase encoding plasmid. Of the remaining 15 PPNG isolated, nine carried this plasmid combined with the 24.5 MDa plasmid and six without. No strains carrying the $4.4 \mathrm{MDa}$ plasmid were found.

Given the prominence of the NR/IB-7 isolates in this study we examined the distribution of these strains between patient groups (table 3 ), and there was no significant difference $(\mathrm{p}=0.9)$.

\section{Discussion}

This study used a number of typing schemes, auxotyping, serotyping, plasmid analysis and antibiotic susceptibility profiles to examine isolates of $N$ gonorrhoeae from an African country. Using these techniques in combination, we have identified a cluster of isolates that belong to a single $\mathrm{A} / \mathrm{S}$ class, NR/IB-7, and are penicillin resistant either by plasmid-mediated production of penicillinase $(77 \%)$ or chromosomal mutations (23\%).

The patients from whom these isolates had been collected were treated with tetracycline, the first line treatment for gonorrhoea in these clinics. Reduced susceptibility to tetracycline was documented, although only five clinical failures were identified. All the clinical failures were isolated from men with urethritis who were seen routinely for follow-up. The failure rate in men was, therefore, $7 \%$. Several prostitutes did not show-up for their follow-up appointment, so that it is impossible to estimate the rate of treatment failure among these women. We did not find any high-level plasmid-mediated resistance to tetracycline as yet but widespread use of this antibiotic may eventually select for tetracycline-resistant $N$ gonorrhoeae (TRNG). Spectinomycin, ceftriaxone and ciprofloxacin are the antibiotics recommended by the World Health Organisation for the treatment of gonorrhoea. ${ }^{20}$ Gonococcal isolates with levels of reduced in vitro 
susceptibility to ceftriaxone and ciprofloxacin found in this study are likely to be sensitive to treatment with single doses of either $500 \mathrm{mg}$ of ciprofloxacin or $250 \mathrm{mg}$ of ceftriaxone. The few reports of clinical failure with ciprofloxacin have been with isolates with MICs of $\geqslant 0.25 \mathrm{mg} / \mathrm{l}$ treated with a $250 \mathrm{mg}$ dose. ${ }^{21}$

However, all these antibiotics are expensive and alternative therapies need to be considered. We tested for susceptibility to thiamphenicol, which is suggested as second line therapy by the WHO, but there were also significant numbers of isolates with a MIC $>1 \mathrm{mg} / \mathrm{l}$ a level associated with clinical failure. ${ }^{22}$ This is not surprising as chromosomal resistance to penicillin has been associated with resistance to chloramphenicol, ${ }^{23}$ a drug related to thiamphenicol. Of the antibiotics tested, ciprofloxacin appears the most suitable to eradicate these resistant strains as it is effective given orally and is the cheapest of the three recommended first line therapies. Whether ciprofloxacin should be used as the first line treatment of all patients with urethritis or given only to those who have failed a 5-day course of tetracycline will depend on a number of factors including the frequency of chlamydial infection, the availability of the Gram stain, the rate of failure with tetracycline and the financial capacity of the government and of the patients.

The high prevalence of PPNG found in this study $(49 \%)$ is similar to that reported from other African countries. ${ }^{2-11}$ There has been a disturbing increase in PPNG infections in West Africa during the last 10 years; in Senegal two studies have shown an increase, from $7 \%$ to $21 \%$ between 1982 and $1986^{\circ}$ and from $4 \%$ to $24 \%$ between 1981 and $1988 ;^{8}$ in Cameroon an increase from $32 \%$ to $59 \%$ has been reported ${ }^{10}$ and in The Gambia $8 \%$ of infections were caused by PPNG in $1981^{2}$ compared with $49 \%$ in this study. We also identified only the 3.2 MDa penicillinase encoding plasmid in this gonococcal population whereas both the $3 \cdot 2$ $\mathrm{MDa}$ and 4.4 MDa plasmids have been reported previously ${ }^{3679}$ including an earlier study from The Gambia. ${ }^{5}$ PPNG harbouring the 3.2 $\mathrm{MDa}$ plasmid originated in Africa whereas the PPNG harbouring the $4.4 \mathrm{MDa}$ plasmid originated in Asia. The presence of the $3.2 \mathrm{MDa}$ penicillinase encoding plasmid alone suggests that these isolates may have been indigenous in nature. Chromosomal resistance to penicillin has not been so well documented, although Lind $e t a l^{9}$ found an increase of CMRNG in Senegal from $12 \%$ in 1982 to $31 \%$ in 1986 compared with $52 \%$ (44 of 84 nonPPNG) in this study.

The finding of a single A/S class, NR/IB-7, dominant in a gonococcal population is unusual. In the gonococcal population from our clinic in London NR/IB-7 isolates only account for $0.7 \%(22 / 3000)$ of the total population tested between 1988-91 (unpublished results). NR/IB-7 isolates were not found in a previous study from The Gambia ${ }^{5}$ and it is, therefore, possible that the patients in this study had acquired serovar-specific immunity $^{14}$ to those $\mathrm{A} / \mathrm{S}$ classes present in previous years but had not yet developed such immunity to the IB-7 isolates. The NR/IB-7 isolates were evenly distributed among the different patient groups, which consisted primarily of female prostitutes and their male contacts, who probably represent a core group spreading highly antibiotic-resistant $N$ gonorrhoeae. This would only be true if the isolates were a representative sample of the total gonococcal population seen in these clinics. The isolates were collected consecutively but the total number characterised in London was influenced by survival during storage in The Gambia and transport to the UK. Of the 249 isolates originally collected $68 \%$ were tested. Prostitutes were over represented as some of them had been asked to attend. As in many African countries, Gambian patients often try self-administration of antibiotics and only attend a clinic when such a treatment fails. This would also select for antibiotic resistant strains.

The techniques we have used have identified a relatively homogenous gonococcal population with a low number of $\mathrm{A} / \mathrm{S}$ classes. In addition, this population consists of a cluster of isolates, NR/IB-7, that may have originated from a single source. The NR/IB-7 isolates were evenly distributed among the patient population of which the vast majority were prostitutes and their contacts. Of the 18 women classified as STD clinic attenders, it is possible some were unconfirmed prostitutes. This readily identifiable core group should be targeted to eradicate these particularly antibiotic resistant strains.

We thank Dr David Mabey for helpful suggestions and Syva Co, Palo Alto, USA for the kind gift of the monoclonal antibodies. The work in The Gambia was supported by the Medical Research Council.

1 Meheus A, De Schryver A. Sexually transmitted diseases in the Third World. In: Harris JRW, Forster SM, eds Sexually Transmitted Diseases and AIDS. London, ChurchSexually Transmitted Diseases and

2 Mabey DCW, McRobbie I. Penicillinase-producing Neisseria gonorrhoeae. BMf 1982;285:571-2.

3 Bogaerts J, Vandepitte J, Van Dyck E, Vanhoot R, Dekegel $M$, Piot P. In vitro antimicrobial sensitivity of Neisseria gonorrhoeae from Rwanda. Genitourin Med 1986; 62:217-20.

4 Osoba AO. Overview of penicillinase-producing Neisseria gonorrhoeae in Africa. Afr $\mathcal{f}$ Sex Transm Dis 1986; 2:51-64.

5 Johnson AP, Abeck D, Wall RA, Mabey DCW, TaylorRobinson D. Plasmid content, auxotype and protein-I serovar of gonococci isolated in The Gambia. Epid Infect 1987;99:669-74.

6 Osoba AO, Johnston NA, Ogunbanjo BO, Ochei J. Plasmid profiles of Neisseria gonorrhoeae in Nigeria and efficacy of spectinomycin in treating gonorrhoea. Genitourin Med 1987;63:1-5

7 Mason PR, Gwanzura L, Latif AS, Marowa E. Antimicrobial susceptibility of Neisseria gonorrhoeae in Harare, Zimbabwe. Sex Transm Dis 1990;17:63-6.

8 Van de Velden L, Van Dyck E, De Schampheleire I Dankaratou Y, Piot P. Neisseria gonorrhoeae à Pikine (Senegal): surveillance de la sensibilité aux antibiotiques. Ann Soc Belg Med Trop 1990;70:99-103.

9 Lind I, Arborio M, Benzton MW, et al. The epidemiology of Neisseria gonorrhoeae isolates in Dakar, Senegal 1982-86. antimicrobial resistance, auxotypes and plasmid profiles. Genitourin Med 1991;67:107-13.

10 Abong BT, Fonkoua MC, Guibourdenche M, Riou JY, Ndayo WM, Garrigue G. Analyse de 190 souches de Neisseria gonorrhoeae isolées à Yaounde de 1984 à 1987 :
auxotypes contenus plasmidiques, sensibilité aux antiauxotypes contenus plasmidiques, sensibilite aux anti-
biotiques. Bull Soc Pathol Exot Filiales 1991;84:136-44. 
11 Plummer FA, D'Costa LJ, Nzanse H, et al. Development of endemic penicillinase-producing Neisseria gonorrhoeae in Kenya. In: Schoolnik GK, ed. The Pathogenic Neisseriae, Washington DC. American Society of Microbiology 1985:101-4.

12 Catlin BW. Nutritional profiles of Neisseria gonorrhoeae, Neisseria meningitidis and Neisseria lactamica in chemically defined media and the use of growth requirements for gonococcal typing. I Infect Dis 1973;128:178-94.

13 Knapp JS, Tam MR, Nowinski RC, Holmes KK, Sandstrom EG. Serological classification of Neisseria gonorrhoeae with the use of monoclonal antibodies to gonococcal outer membrane protein I. $\mathcal{F}$ Infect Dis 1984;150:44-8.

14 Plummer FA, Simonesen JN, Chubb H, et al. Epidemiologic evidence for the development of serovar-specific immunity after gonococcal infection. I Clin Invest 1989;83:1472-6.

15 Pepin J, Morgan G, Dunn D, et al. HIV-2 induced immunosuppression among asymptomatic West African prostitutes: evidence that HIV-2 is pathogenic, but less so than HIV-1. AIDS 1991;5:1165-72.

16 Copley CG, Egglestone SI. Auxotyping of Neisseria gonorrhoeae isolated in the United Kingdom. $\mathcal{F}$ Med Microbiol.
1983;16:295-302.

17 Bygdeman SM, Gillenius EC, Sandstrom EG. Comparison of two different sets of monoclonal antibodies for the Schoolnik GK, ed. The DC American Society for Microbiology 1975:31-6.

18 Birnboim HC, Doly J. A rapid alkaline extraction procedure for screening recombinant plasmid DNA. Nucleic Acid Res for screening reco

19 Ison CA, Branley NS, Kirtland K, Easmon CSF. Surveillance of antibiotic resistance in clinical isolates of Neisseria gonorrhoeae. BMF 1991;303:1307.

20 World Health Organization. STD Treatent Strategies. World Health Organization, Geneva 1989;WHO/VDT/89.447.

21 Gransden WR, Warren C, Phillips I. 4-quinolone-resistant Neisseria gonorrhoeae in the United Kingdom. $f$ Med Microbiol 1991;34:23-7.

22 Nzanse H. D'Costa L, Owili D, Ilako F, Achola N. Treatment of gonorrhoea with single dose thiamphenicol in Kenya. Sex Transm Dis 1984;11(suppl 1):376-8.

23 Ison CA, Bindayna KM, Woodford N, Gill MJ, Easmon CSF. Penicillin and cephalosporin resistance in gonococci. Genitourin Med 1990;60:351-6. 